\title{
Early steps in the radiation of notoungulate mammals in southern South America: A new henricosborniid from the Eocene of Patagonia
}

\author{
Nicolás Bauzá, Javier N. Gelfo, and Guillermo M. López \\ Acta Palaeontologica Polonica 64 (3), 2019: 597-603 doi:https://doi.org/10.4202/app.00565.2018
}

Here we describe a new notoungulate mammal from the early Eocene (Itaboraian SALMA) of Chubut, Argentinian Patagonia, from the localities of Las Flores and Las Violetas Farm, represented by fragments of maxilla and isolated teeth. The specimens were found in the Las Flores Formation, Río Chico Group, and assigned to the Henricosborniidae, a primitive family within the order Notoungulata. Orome deepi gen. et. sp. nov. differs from other henricosborniids in a less developed metacone column in the upper molars, a larger metaloph in the third upper molar and a larger mean size. The morphometric analysis does not show any difference between the individuals of the two studied localities. The new addition to the henricosborniid diversity in Patagonia allows to provide a better understanding of the early radiation of notoungulates in South America.

Key words: Mammalia, Notoungulata, Paleogene, Eocene, Patagonia, Argentina.

Nicolás Bauzá [bauzan@fcnym.unlp.edu.ar], División Paleontología de Vertebrados, Museo de La Plata. Paseo del Bosque s/n B1900FWA, La Plata, Buenos Aires, Argentina and Consejo Nacional de Investigaciones Científicas y Técnicas (CONICET), Argentina. Javier N. Gelfo [jgelfo@fcnym.unlp.edu.ar ], División Paleontología de Vertebrados, Museo de La Plata. Paseo del Bosque s/n B1900FWA, La Plata, Buenos Aires, Argentina; Consejo Nacional de Investigaciones Científicas y Técnicas (CONICET), Argentina; Facultad de Ciencias Naturales y Museo de La Plata, Universidad Nacional de La Plata, Buenos Aires, Argentina. Guillermo M. López [glopez@ fcnym.unlp.edu.ar], División Paleontología de Vertebrados, Museo de La Plata, Paseo del Bosque s/n B1900FWA, La Plata, Buenos Aires, Argentina; Facultad de Ciencias Naturales y Museo de La Plata, Universidad Nacional de La Plata, Buenos Aires, Argentina. 
Attribution License (for details please see creativecommons.org), which permits unrestricted use, distribution, and reproduction in any medium, provided the original author and source are credited.

\footnotetext{
Foris Full text $(287.9 \mathrm{kB})$ ।

For Supplementary file $(103.7 \mathrm{kB})$
} 